\title{
Erratum to: Size relationships of different body parts in the three dipteran species Drosophila melanogaster, Ceratitis capitata and Musca domestica
}

\author{
Natalia Siomava $^{1} \cdot$ Ernst A. Wimmer $^{1} \cdot$ Nico Posnien $^{1}$
}

Published online: 28 May 2016

(C) Springer-Verlag Berlin Heidelberg 2016

\section{Erratum to: Dev Genes Evol}

DOI: 10.1007/s00427-016-0543-6

After the online publication of the above mentioned article, we realized that important information in Fig. 1 got lost during the

production process. Besides the lack of the scale bar in Fig. 1c, labels for landmarks $1-10$ are missing in the schematic wing of Fig. 1c. Unfortunately, we did not realize these mistakes during the proof-reading and we apologize for any invonvenience caused by this.
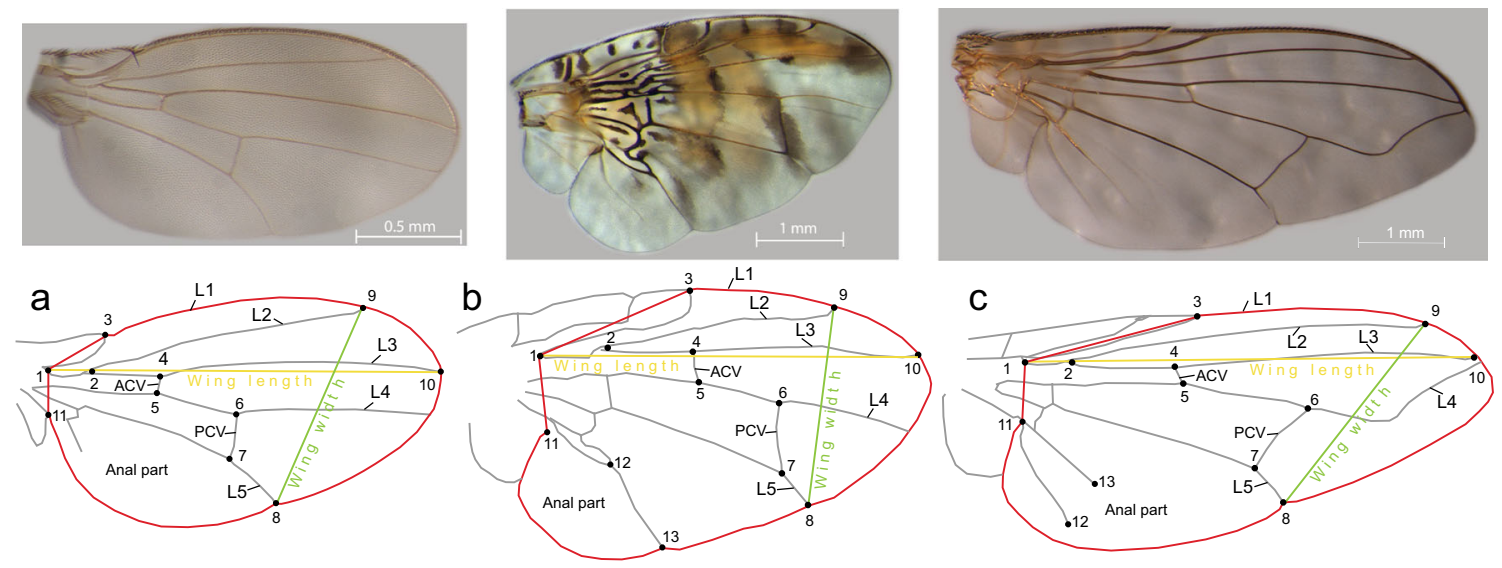

Fig. 1 Wing outlines with landmarks and measurements. Wing length, width and outline for the manually measured area (red line) and

capitata (b) and $M$. domestica (c). The landmark coordinates were used to landmarks from 1 to 11 in D. melanogaster (a) and from 1 to 13 in $C$. extract wing length, width and WCS. $A C V$ corresponds to anterior cross vein, $P C V$ posterior cross vein, $L 2-L 5$ longitudinal veins

The online version of the original article can be found at http://dx.doi.org/ 10.1007/s00427-016-0543-6.

Ernst A. Wimmer

ewimmer@gwdg.de

$\triangle$ Nico Posnien

nposnie@gwdg.de

1 Johann-Friedrich-Blumenbach-Institute of Zoology and Anthropology, Göttingen Center for Molecular Biosciences (GZMB), Department of Developmental Biology, Georg-August-University Göttingen, Ernst-Caspari-Haus, Justus-von-Liebig-Weg 11, 37077 Göttingen, Germany 